\title{
Una ecología política de minería indígena responsable: Dilemas, disputas y desafíos en la comunidad Shuar de Congüime de la Amazonía ecuatoriana
}

\section{A Political Ecology of Responsible Indigenous Mining: Dilemmas, Disputes and Challenges in the Shuar Community of Congüime in the Ecuadorian Amazon}

\author{
RICKARD LALANDER ${ }^{1}$ \\ Universidad de Södertörn, Suecia \\ María Beatriz Eguiguren Riofríoº \\ ANa Karina Vera ${ }^{3}$ \\ MALENy REYES ${ }^{4}$ \\ GABRIELA ESPINOSA ${ }^{5}$ \\ Universidad Técnica Particular de Loja, Ecuador \\ MAGNUS LEMBKE ${ }^{6}$ \\ Universidad de Estocolmo, Suecia
}

1. Sociólogo y politólogo. Catedrático de Universidad (Full Professor) en estudios de desarrollo y ambiente. Universidad de Södertörn, Suecia; Catedrático y PhD. en estudios culturales/estudios latinoamericanos, Universidad de Helsinki, Finlandia; Investigador asociado, Universidad Técnica Particular de Loja, Ecuador. Mail: rickard.lalander@sh.se.

2. Doctora en Ciencias Sociales. Docente investigadora del Departamento de Ciencias Jurídicas. Directora del Observatorio de Conflictos Socioambientales, Universidad Técnica Particular de Loja. Mail: mbeguiguren@utpl.edu.ec.

3. Magister en Gestión de la Responsabilidad Social Corporativa, Docente e Investigadora del Departamento de Ciencias Sociales y Jurídicas de la Universidad Técnica Particular de Loja, Ecuador. Mail: akvera@utpl.edu.ec.

4. Magíster en Gestión de Desarrollo Local Comunitario. Docente e investigadora del Departamento de Ciencias Sociales-Observatorio de Conflictos Socioambientales de la Universidad Técnica Particular de Loja, Ecuador. Mail: mgreyes@utpl.edu.ec.

5. Magister en Gestión del desarrollo Local y Comunitario. Candidata doctoral en Ciencias Sociales en la línea de cultura, desarrollo humano e intervención social, Universidad Pablo de Olavide, Sevilla. Docente e Investigador de la Universidad Técnica Particular de Loja. Mail: mgespinosa@utpl. edu.ec . 
RESUMEN Desde 2016, la comunidad indígena Shuar de Congüime en la Amazonía ecuatoriana tiene la concesión para extraer oro en su territorio mediante su empresa comunitaria Exploken Minera. Con su misión de una minería socio-ecológicamente responsable, invirtiendo los ingresos en la comunidad y sin usar químicos o metales pesados, este modelo único se contrasta con la extracción minera transnacional e ilegal en territorios indígenas. Con inspiración teórica y metodológica de la ecología política, justicia ambiental y el post-desarrollo, así como la conceptualización de utopías reales, este estudio etnográfico trata de las experiencias de gobernanza y justicia socioambiental de la empresa comunitaria y los dilemas, disputas y desafíos que emergen en la comunidad con esta nueva situación. El resultado indica que varios desafíos estructurales siguen sin resolverse. Si bien las experiencias de responsabilidad socioecológica de Exploken constituyen una opción ante el extractivismo destructivo y considerando la mejora de las condiciones de vida de muchas familias Shuar, surgieron nuevas tensiones sociales en Congüime, incluso transformaciones de las estructuras de poder social.

PALABRAS CLAVE Amazonía ecuatoriana; Ecología política; Justicia socioambiental; Minería indígena; Shuar.

ABSTRACT Since 2016, the Shuar indigenous community of Congüime in the Ecuadorian Amazon has held the gold mining concession in its territory through the community company Exploken Minera. With its mission of socially and ecologically responsible mining, investing the incomes in the community and without using chemicals or heavy metals, this unique model contrasts with transnational and illegal mining in indigenous territories. The present ethnographic study, which draws theoretical and methodological inspiration from political ecology, environmental justice, post-development and the conceptualization of real utopias, deals with the experiences of socio-environmental governance and justice of the Shuar mining company, and the dilemmas, disputes and challenges that emerge in the community in this unprecedented situation. The result indicates that structural challenges remain unsolved. While Exploken's experiments in socio-ecological responsibility constitute an alternative to destructive extractivism, and considering the improved living conditions enjoyed by many Shuar families, new social tensions have emerged in Congüime, including transformations of social power structures.

6. Doctor en Ciencia Política, Departamento de Ciencia Política de la Universidad de Estocolmo; Profesor, Investigador y Director de estudios, Nordic Institute of Latin American Studies, Universidad de Estocolmo, Suecia. Mail: magnus.lembke@lai.su.se. 
KEYWORDS Amazonía ecuatoriana; Ecología política; justicia socioambiental; Minería indígena; Shuar.

\section{Contextualización}

Ustedes conocen esta minería. Es un ejemplo, un modelo, el primero y lo único que está en el mundo, puesto super internacional, que es el único Shuar. Si hay hombres y mujeres Shuar que conforman una pequeña compañía y quiénes están día a día ahí, impulsando estos frentes de trabajo y dando fuentes de trabajo, no solamente a la persona de aquí 7 .

En la parte ambiental, bueno, desde que nosotros cogimos hemos estado llevando como debe ser la minería. Porque nosotros no utilizamos mercurio, nosotros no usamos ningún producto químico. Pero, sin embargo, esto sigue en contaminación, lleno de mercurio porque ellos, los ilegales usaron mercurio por kilos. Entonces, esto estaba lleno, lleno. Pero, como nosotros vimos escombreras que dejaron los ilegales fuimos relavando. Entonces, de ahí fuimos recuperando lo poco que perdimos ${ }^{8}$.

Desde el año 2016, la pequeña comunidad Shuar Kenkuim (Congüime) ${ }^{9}$ en la Amazonía sur ecuatoriana tiene la concesión para extraer oro en un área de 410 hectáreas, ubicadas en Congüime ${ }^{10}$, originando un modelo de desarrollo local alternativo al extractivismo contaminador tradicional, en el que la comunidad indígena Shuar desempeña un papel esencial para dinamizar la economía y las condiciones de vida de su población. Ya en el 2012, se establecieron las negociaciones entre el Estado y la comunidad Shuar para crear la primera empresa minera indígena y en el 2014 se creó la Compañía Exploken Minera S.A. que eventualmente obtuvo la concesión e inició la extracción de oro en 2016. Paralelamente, como se refleja en las declaraciones de los representantes Shuar - Blanca Ankuash y Alipio Wajari, presidenta y gerente general respectivamente de Exploken Minera hasta 2019 - su proyecto representa un gran desafío en realizar una actividad minera responsable en el que se responda por el bienestar social de la comunidad, además de remediar los daños causados por décadas de extractivismo privado e ilegal.

Históricamente, los Shuar son conocidos como un pueblo guerrero en la Amazonía ecuatoriana y peruana. En la Amazonía sur ecuatoriana hay vastos territorios so-

7. ANKUASH QUIZHPE, entrevista, Congüime, 13 de febrero 2019.

8. WAJARI, entrevista, Congüime, 12 de febrero 2019.

9. Congüime es una españolización de Kenkuim, el nombre de la localidad en el idioma Shuar. 10. MINISTERIO DEL AMBIENTE (2016) p. 12. 
beranos Shuar. A través de las décadas han luchado por la autodefinición como Shuar y como indígenas y en contra de la colonialidad y los proyectos extractivistas, y para defender sus prácticas comunitarias, la valoración de la naturaleza, y su identidad étnico-cultural ${ }^{11}$. Cuestiones de desarrollo, territorio, ambiente y cultura se han convertido en elementos importantes para los pueblos indígenas, más aún cuando están ligados a actividades extractivas. Estos pueblos tradicionalmente se han establecido como defensores y protectores de la Pachamama (Madre Tierra).

El caso de los Shuar en Congüime representa un contexto único a nivel latinoamericano. Exploken Minera es el primer caso de empresa minera indígena en Sudamérica, misma se ha destacado por su perfil de responsabilidad social y ecológica y que ha sido clasificado como un referente de gobernanza ambiental y un modelo alternativo al extractivismo contaminador tradicional. Actualmente, la comunidad indígena cumple el rol de extractor minero ecológicamente responsable, contrapuesto a la percepción tradicional de las empresas mineras que han sido consideradas como enemigos y opresores de los pueblos indígenas y la naturaleza, explotando y contaminando sus territorios. Debe mencionarse que Congüime está rodeada de otros proyectos mineros transnacionales de gran escala, como el proyecto Fruta del Norte de Lundin Gold en Yantzaza y el proyecto Mirador de la empresa china Ecuacorriente en El Pangui ${ }^{12}$, así que, en este contexto, el proyecto minero comunitario se destaca como un modelo alternativo de pequeña escala y de perfil ecológico.

Conceptualmente, el extractivismo en el debate académico se refiere principalmente a los sectores minero e hidrocarburífero, aunque una definición más amplia y precisa del extractivismo es: “... un tipo de extracción de recursos naturales, en gran volumen y a alta intensidad, dirigida principalmente a la exportación como materia prima, sin o con un mínimo procesamiento" ${ }^{13}$. Evidentemente, nuestro caso de estudio realmente no se clasifica como "extractivismo" según la definición de Gudynas, sino que más bien los Shuar de Congüime podrían ser clasificados como lavadores de oro, pero con maquinaria, es decir, ya que no se trata de extracción en volúmenes grandes, y tampoco de alta intensidad. Nuestro caso tampoco incluye la dimensión económica colonialista de Norte-Sur, que tan frecuentemente caracteriza a los proyectos extractivistas. Formalmente, es una operación de minería en pequeña escala, con sus características de ser comunitaria de los Shuar y el perfil de responsabilidad social y ecológica. Un punto de partida es que el encuentro entre la sociedad tradicional indígena y la sociedad que penetra la comunidad a través del extractivismo, se manifiesta, por un lado, a través de la resistencia local y, por otro, a través de una

11. BUSTAMANTE (1988); KARSTEN (2000); FERNÁNDEZ-SALVADOR (2018).

12. VAN TEIJLINGEN et al. (2017); FERNÁNDEZ-SALVADOR (2018).

13. GUDYNAS (2015) p. 13; SVAMPA (2019). 
apropiación local comunitaria, en este caso mediante la creación de la empresa minera Shuar.

Con inspiración teórica y metodológica de la ecología política, justicia ambiental, el post-desarrollo, y la teorización sobre la construcción de las utopías reales, este artículo trata de las experiencias de gobernanza socioambiental de la empresa minera Shuar y los dilemas, disputas y desafíos que emergen en la comunidad indígena con esta nueva situación. Lo que tienen en común las aproximaciones teóricas mencionadas es sobre todo la preocupación por la crisis socioecológica y un cuestionamiento del capitalismo global y de la conceptualización de desarrollo, entendido como progreso, crecimiento económico y modernidad según los parámetros occidentales, los cuales subordinan los valores locales de cultura, identidad, conocimientos y tradiciones de las poblaciones locales al valor superior económico ${ }^{14}$. Desde la ecología política se destaca la importancia de justicia socioambiental a nivel local y el respeto por los valores, tradiciones, ontologías y epistemologías de las poblaciones que tradicionalmente han sido marginalizadas y víctimas del extractivismo con sus consecuencias socioecológicas ${ }^{15}$. Con respecto a la conceptualización de las utopías reales, un regreso radical y rápido hacia una sociedad indígena tradicional puede entenderse como utópico. Pero, si comprendemos el proceso como gradual y contextualmente pragmático, según la teorización de Eric Olin Wright (2010), nuestro caso sugiere que la minería socio-ecológicamente responsable de los Shuar en Congüime podría interpretarse como un ejemplo de una utopía real. Es decir, se trata de una experiencia de resguardar y fortalecer su cultura y su territorio mediante un compromiso entre resistencia y adaptación en un mundo ampliamente condicionado por las lógicas del capitalismo extractivista global.

Sin dejar de reconocer los importantes logros y avances de este proyecto socioecológicamente responsable, no obstante, un punto hipotético de partida del artículo es que el establecimiento de la pequeña minería comunitaria supuestamente conllevaría una transformación de las estructuras socioculturales, políticas y económicas, mediante el control de las actividades mineras por parte de la comunidad Shuar. Pero, pronto emergieron nuevos dilemas, disputas y desafíos en la comunidad. El dilema superior y principal es, evidentemente el de ser o no ser empresa minera comunitaria. Este dilema principal dio origen a una serie de otros (sub-)dilemas, disputas y desafíos. Otros (sub-)dilemas, disputas y desafíos que se desarrollarán más en adelante en las secciones analíticas tienen que ver con los impactos de la minería en la cultura Shuar, la responsabilidad socioecológica, la transformación de las estructuras sociales y del poder a nivel de la comunidad, incluso el fortalecimiento relativo de las mujeres

14. ESCOBAR (2006); ACOSTA (2010); LALANDER (2014; 2016); HOLIFIELD (2015).

15. ESCOBAR (2006). 
en la comunidad. Sobre el enfoque en las disputas, debemos clarificar que éstas más que todo se expresan en las diferentes perspectivas y percepciones de los actores, y cómo el dilema central del estudio -ser o no ser empresa minera- se refleja en las dinámicas e interacciones socioculturales, asimismo considerando las dimensiones económicas y ambientales.

Consecuentemente, el objetivo del artículo es explorar y problematizar las experiencias de la empresa minera Shuar Exploken Minera en Congüime. Más específicamente, se analizarán los dilemas, disputas y desafíos que han emergido en este nuevo contexto de pequeña minería comunitaria indígena. A partir del marco teórico de la ecología política, la justicia ambiental, el post-desarrollo y la teorización sobre la construcción de las utopías reales, las preguntas investigativas que guiarán el análisis son:

¿Cómo se refleja el dilema central del estudio - ser o no ser empresa minera indígena en las dinámicas e interacciones socioculturales de Congüime?

¿Cuáles son y cómo se reflejan los emergentes sub-dilemas, disputas y desafios generados por el establecimiento de la empresa Exploken Minera entre los actores locales Shuar en Congüime y sus estructuras de poder local?

¿Cómo se articulan los valores y perspectivas socioculturales, ecológicos, epistémicoontológicos y económicos por los actores desde la autoidentificación como pueblo Shuar y en relación al nuevo proyecto minero indígena?

A través del enfoque analítico en estas preguntas se enfatizan los contrastes y diferentes posiciones en las percepciones e interpretaciones de los actores involucrados sobre la significancia y el impacto socioambiental de la existencia y los avances de Exploken Minera en Congüime. Aunque la minería no es un fenómeno novedoso para la cultura Shuar tradicional, el hecho de que una mayor parte de la economía local se dedique a esta actividad - ahora en la legalidad y dirigida por los propios Shuar - dará lugar al surgimiento de nuevos actores sociopolíticos y, por lo tanto, a una reconfiguración del equilibrio de poder local. Esta transformación sociopolítica constituye el núcleo de nuestra aproximación analítica. Es importante aclarar, sin embargo, que el estudio no tratará de manera detallada las características técnicas y/o ecológicas de las actividades de Exploken Minera. Más bien, se enfocarán en primer lugar los aspectos socioculturales.

A nivel nacional y coyuntural, se debe clarificar el contexto político de Ecuador post-2008 para una mejor comprensión del caso de Congüime. A partir del año 2008, Ecuador tiene la Constitución más progresista del mundo en cuanto a los derechos propios de la naturaleza y una de las más avanzadas en el reconocimiento de los derechos de los pueblos étnicamente definidos. Con la Constitución de 2008, Ecuador se declara también como un Estado Plurinacional, es decir un reconocimiento de las 
reivindicaciones indígenas y su identificación colectiva como pueblos y nacionalidades indígenas ${ }^{16}$. Asimismo, la conceptualización ético-filosófica indígena del Sumak Kawsay (Buen-vivir) sobre la convivencia armoniosa entre seres humanos y con la naturaleza se incorporó como visión de país en la nueva constitución y los planes nacionales de desarrollo. Aun así, la extracción de los recursos naturales, principalmente minerales e hidrocarburos ha incrementado en el país, incluso en los parques nacionales y los territorios indígenas ${ }^{17}$.

Es importante destacar, sin embargo, las contradicciones inherentes en la misma Constitución progresista, para contrastar los derechos ambientales y étnico-territoriales con los derechos del Estado de explotar y comercializar los recursos naturales. En el contexto de las nacionalizaciones de las industrias vitales -hidrocarburos y minería- la Constitución ecuatoriana declara que la industrialización y la comercialización de los recursos naturales son prioridades claves para el Estado, empero considerando los derechos de la naturaleza y los pueblos indígenas y, asimismo, destacando que los ingresos derivados de la extracción serán dirigidos al bien común

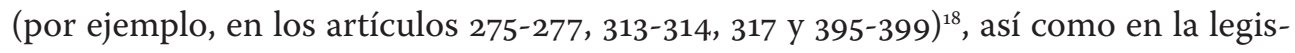
lación secundaria y el Plan Nacional de Desarrollo para el Buen Vivir ${ }^{19}$. Es en este contexto político-constitucional de Ecuador - con su nuevo "perfil verde" - que nace el proyecto innovador de los Shuar de Congüime.

Debemos clarificar, no obstante, que el enfoque de nuestro artículo no es, en primer lugar, un análisis del extractivismo, la reprimarización, y los derechos de los pueblos indígenas en el nuevo contexto constitucional ecuatoriano ${ }^{20}$. Más bien, se ofrece una presentación analítica de un caso local en el cual la comunidad indígena tomó la iniciativa para encargarse de la extracción de oro en la localidad según sus criterios

16. LALANDER y LEMBKE (2018a).

17. LALANDER (2014; 2015; 2016); SACHER (2015); LALANDER y KRÖGER (2016); VAN TEIJLINGEN et al. (2017); LALANDER y MERIMAA (2018); FERNÁNDEZ-SALVADOR (2018). 18. REPÚBLICA DEL ECUADOR (2008).

19. SENPLADES (2009; 2013); LALANDER (2014; 2015); LALANDER y MERIMAA (2018). Debemos mencionar la importancia de la fuerza histórica organizativa del movimiento indígena ecuatoriano a nivel nacional detrás de estos reconocimientos constitucionales, especialmente desde los años 90. Asimismo, ya en el año 1964, los Shuar fueron los primeros de los pueblos indígenas en fundar su propia organización: la Federación Shuar.

20. Hay abundantes aportes académicos sobre estos temas a partir de 2008. Si bien es cierto que el contexto histórico de Ecuador es importante y además impacta a todas actividades económicas en regiones afectadas por la extracción de recursos naturales, como es el caso de los territorios Shuar, en nuestro artículo esta dimensión de la economía política nacional constituye sobre todo el fondo 
de responsabilidad socioecológica, por ende, asumiendo asimismo una posición que rompe con la actitud típica de las comunidades indígenas frente a la minería.

Metodológicamente, desde nuestras suposiciones teóricas de la ecología política, la justicia socioambiental, el postdesarrollo y las utopías reales, el artículo se ha beneficiado de la lectura crítica del debate académico sobre extractivismo en la Amazonía, e igualmente de la cobertura del caso de Congüime en la prensa ecuatoriana y reportes de conflictividad socioambiental en la localidad. Sin embargo, el componente metodológico más importante es el trabajo etnográfico en el campo con los Shuar de Congüime, con las conversaciones informales y las entrevistas abiertas y semiestructuradas con los actores - individualmente y en grupo - así como las observaciones participativas en la localidad, de manera más informal en 2012 y a partir de 2016 y más sistemáticamente desde el inicio del 2019.

Asimismo, se organizó un taller participativo con los actores el 21 de febrero del 2019 y se había extendido la invitación a todos los miembros de la comunidad Kenkuim. En el taller los miembros del equipo de investigación (los autores de este artículo) se dividieron y se organizaron mini-talleres, con por lo menos un representante de Exploken Minera y un investigador en cada grupo. Es importante enfatizar, consecuentemente, que se trata de un trabajo en el campo, y no solamente sobre los actores locales sino en colaboración con ellos $^{21}$. En varias ocasiones, no solamente en el taller, hemos compartido los avances de investigación con los actores para darles la oportunidad de corregirnos y criticarnos según sus perspectivas. Alrededor de 100 conversaciones se realizaron en 2019, y unas docenas entre 2016 y 2018. Con varios de los protagonistas, se realizaron varias entrevistas en diferentes ocasiones en 2019, tanto las entrevistas individuales y las colectivas. La gran mayoría de las entrevistas fueron grabadas y transcritas y se guardan en los archivos de los autores. Todos los actores fueron informados de los objetivos de la investigación y expresaron consenso en cuanto a la grabación y la publicación de los datos obtenidos mediante las entrevistas.

Luego de esta contextualización introductoria, la disposición del artículo es la siguiente. Primero, se presenta el marco teórico, seguido por dos apartados histórico-contextuales, el primero enfocando el contexto de los Shuar de Congüime y el extractivismo amazónico, y el segundo describe el nacimiento de Exploken Minera.

contextual. Particularmente, nuestro caso de estudio se distingue cualitativamente de la mayoría de los estudios publicados sobre extractivismo y comunidades indígenas en América Latina, ya que el modelo de la empresa minera Shuar de Congüime rompe con la manera tradicional de resistencia y/o subordinación al extractivismo capitalista nacional o tradicional.

21. LEMBKE et al. (2020). 
Después, se presenta el análisis del caso Exploken Minera, a partir de las preguntas investigativas y los dilemas, disputas y desafíos del estudio. El artículo se redondea con algunas conclusiones pertinentes.

\section{Marco teórico: Ecología política, justicia ambiental, post-desarrollo y las uto- pías reales}

Teóricamente, tanto la ecología política, la justicia ambiental y el campo del postdesarrollo tratan de temas de poder, injusticias, dominación y las dimensiones socioculturales de los cambios climáticos y ambientales, entre otros, provocados por las actividades extractivas y capitalistas. Para Arturo Escobar, la ecología política trata de conflictos y más concretamente los conflictos de distribución ecológica, lo que se refiere a las disputas por el acceso y el control de los recursos naturales, en particular como modo de subsistencia, e incluso los costos de la destrucción ambiental. Existen conflictos de distribución ecológica tanto en las economías, culturas y epistemologías, más allá de la evidente dimensión ecológica ${ }^{22}$. No es una casualidad que Escobar se basa en argumentos de la justicia ambiental en su aporte desde la ecología política, considerando que estas dos tradiciones teóricas gradualmente se han fusionado y que han trabajado los mismos tipos de preguntas sobre injusticias socioambientales desde décadas ${ }^{23}$.

Desde la ecología política se cuestiona el orden jerárquico de valores del "desarrollo sostenible": economía-sociedad-ecología; siempre en este orden, comúnmente reflejado en términos de "capitalismo verde" etcétera ${ }^{24}$. En la ecología política tanto la dimensión sociocultural y la ecológica son generalmente más importantes que la dimensión económica. Esta aproximación crítica igualmente se ha presentado desde hace muchos años de los estudiosos del post-desarrollo, los cuales frecuentemente también trabajan intelectualmente en el campo de ecología política y justicia ambien$\operatorname{tal}^{25}$. No obstante, hablando en términos de los modos de subsistencia de los pueblos indígenas rurales, los tres componentes/valores - economía-sociedad-ecología - están íntimamente integrados, y la tierra y sus riquezas pueden constituir la base económica productiva de la comunidad y al mismo tiempo el territorio tiene significado fundamentalmente cultural, ontológico, epistemológico y espiritual. Es decir, representa una función social que no está considerada en las percepciones capitalistas más

22. ESCOBAR (2006) p. 8. Ver también MARTÍNEZ-ALIER (2002).

23. HOLIFIELD (2015); SVARSTAD y BENJAMINSEN (2020).

24. Ver, por ejemplo, SNEDDON et al. (2006).

25. Por ejemplo, ESCOBAR (2000; 2005; 2006). 
mercantilistas sobre la tierra y los territorios. La crítica post-desarrollista argumenta sobre la importancia de "potenciar las capacidades propias para encontrar otras formas de construir estilos de vida dignos para todos los habitantes del planeta, inspirados en las visiones y propuestas de cada sociedad" ${ }^{26}$. En Ecuador frecuentemente se habla del Buen-vivir/Sumak Kawsay como el camino hacia el postdesarrollo ${ }^{27}$ y el post-extractivismo ${ }^{28}$.

Debemos subrayar que históricamente las identidades étnico-territoriales latinoamericanas han sido fluidas y móviles, particularmente entre los pueblos indígenas amazónicos. A través de la historia, su base e identificación territorial y cultural se ha cambiado o modificado, como consecuencia de, por ejemplo, colonización, búsqueda de terrenos más fértiles, conflictos interétnicos, presencia de misioneros religiosos, migración, urbanización, cambios climáticos, modificaciones de modos de subsistencia, o el establecimiento de industrias extractivas en su territorio, etcétera ${ }^{29}$.

No obstante, en muchas de las contribuciones desde la ecología política, el postdesarrollo, e incluso de los aportes sobre el Buen-vivir/Sumak Kawsay, hemos detectado un alto grado de romantización de "lo local y lo indígena", también evidente en muchas publicaciones sobre la lucha de las poblaciones indígenas, las cuales no problematizan suficientemente el hecho de que existen diferentes preferencias en las comunidades indígenas. Con metáforas sobre el "noble nativo" o el "guardián de la selva" sobre el indígena como la "reserva moral ecológica", que indudablemente existe en las realidades de la Amazonía y otros territorios indígenas, aunque varios de estos autores dejan de aclarar que no siempre están los valores de cultura y ecología superiores

26. ACOSTA (2016) pp. 292-293.

27. ACOSTA (2010); LALANDER (2016); LALANDER y MERIMAA (2018). Para los Kichwa amazónicos, el Sumak Kawsay significa vida en armonía o coexistencia harmoniosa entre seres humanos y con la naturaleza. Conceptualmente, propone otras formas de concebir el entorno humano y que la naturaleza no debe verse como fuerza o factor productivo, sino como parte inherente al ser social. Sumak Kawsay se ha traducido a Buen-vivir en español. Ver CHUJI (2010); LALANDER (2015). Debemos mencionar que durante nuestro trabajo etnográfico en Congüime, observamos que no había mucha conciencia filosófica-ontológica en términos del Buen-vivir/Sumak Kawsay entre los Shuar (en parte por ser una conceptualización Kichwa), si bien es cierto que saben practicar y aplicar los principios éticos y comunitarios de este modelo de vida.

28. GUDYNAS (2015); ACOSTA (2016).

29. LALANDER y LEMBKE (2018a). Sobre la territorialidad en la indigeneidad y viceversa, véase también, por ejemplo: WALDMÜLLER y ALTMANN (2018) y sobre los Shuar: BUSTAMANTE (1988); KARSTEN (2000); FERNÁNDEZ-SALVADOR (2018). 
a los valores materiales y económicos. Esto es desafortunado, ya que, al subordinar las perspectivas identitarias de clase, se crea una discrepancia con respecto a aquellos grupos indígenas que en la defensa de sus modos de subsistencia, los cuales pueden experimentar amenazas relacionadas al extractivismo, con frecuencia se expresa discursivamente desde las comunidades en términos de justicia socioeconómica ${ }^{30}$.

Lo anterior sugiere que debemos adoptar una actitud analítica más realista, en el sentido pragmático. El sociólogo Erik Olin Wright retrata un mundo en el que el cinismo, la burla y el pesimismo son las respuestas hegemónicas a las personas y los colectivos que exigen un cambio emancipatorio y radical hacia el igualitarismo democrático. Dibuja a las sociedades contemporáneas como reinadas por las aversiones posmodernas contra las grandes narrativas, los temores conservadores de una transformación social incontrolable y profunda, y la eterna resistencia de las clases dominantes. Inspirado en una noción gramsciana que enfatiza la creación de instituciones radicalmente diferentes y relaciones sociales que requieren optimismo (y no pesimismo), Wright enfatiza que el optimismo y el utopismo son ingredientes necesarios para un cambio radical, pero al mismo tiempo está consciente de los peligros de navegar en aguas inexploradas hacia un paraíso futuro. Al contrario, identifica un compromiso pragmático entre la utopía y el status quo, bajo la conceptualización de Utopías Reales, consciente de que la noción sui generis es un oxímoron. El camino hacia tales utopías no se caracteriza por una rápida revolución social de carácter marxista, sino por alteraciones graduales de las instituciones existentes, es decir, por procesos anclados en la práctica realista. La verdadera democracia igualitaria es alcanzable en la medida en que aspiramos a nuestros sueños, pero avanzamos de acuerdo con nuestros potenciales humanos reales ${ }^{31}$.

Nuestro enfoque sugiere, considerando lo anterior, que la minería indígena socioecológicamente responsable en Congüime podría interpretarse como un ejemplo de una utopía real. Es decir, se trata de un intento - o un sueño - de preservar y fortalecer una sociedad tradicional mediante la actuación realista sobre una arena definida en gran medida por el capitalismo global y un estado neo-extractivista.

Reconectando a las reflexiones anteriores sobre la romantización de lo indígena y lo local, la historia de las relaciones entre los pueblos indígenas y la sociedad dominante en Ecuador y América Latina proporciona numerosos ejemplos de mestizaje, la hibridación de los sistemas políticos y económicos y el sincretismo religioso. No es sólo una historia de comunidades corporativas indígenas cerradas que no se ven afectadas por procesos y estructuras externas, ni simplemente la historia de un pueblo completamente subsumido bajo fuerzas fuera de su control. Es la historia de la

30. LALANDER y LEMBKE (2018b).

31. WRIGHT (2010) capítulo 1. 
adaptación y la resistencia desde abajo. Mediante la adopción de estrategias ancladas en realidades prácticas, los grupos indígenas siempre han tratado de mantener en la medida de lo posible sus modos de subsistencia tradicionales en medio de inevitables transiciones externamente impuestas y una presión externa insuperable. Por ejemplo, en repetidas ocasiones los pueblos indígenas y otros grupos oprimidos y marginados han logrado desempeñar a diferentes funcionarios estatales y autoridades electas en diferentes niveles del Estado (incluso presidentes de la república), o a veces fructíferamente del lado del Estado en sus luchas contra poderes económicos como los propietarios tradicionales y las empresas capitalistas invasoras ${ }^{32}$.

\section{Contexto histórico de los Shuar de Congüime y el extractivismo amazónico}

La minería artesanal de oro es una tradición milenaria en Ecuador, entre otros, por los indígenas de la Amazonía ${ }^{33}$. Según Alipio Wajari y otras autoridades de Exploken Minera, los antecedentes de los Shuar de Kenkuim "venían realizando la minería artesanal por cientos de años". Al llegar los primeros mineros legales desde Colombia, con su maquinaria pesada, hubo convenios con la comunidad. Después llegaron los mineros ilegales que también llegaron a acuerdos con las familias de la comunidad hasta de ser desalojados mediante la militarización de la zona en $2010^{34}$.

La comunidad de Congüime pertenece administrativamente al cantón Paquisha, en la provincia Zamora Chinchipe de la Amazonía sur ecuatoriana. Geográficamente, está ubicada al pie de la cordillera del Cóndor por la frontera con Perú. La quebrada de Congüime desemboca sus aguas en el río Nangaritza. Según datos de la directiva de Exploken y de los voceros principales de la comunidad que tiene entre 650 y 700 habitantes. Históricamente, la localidad que desde los años 70 se conoce como Congüime ya era territorio Shuar, antes del establecimiento de las primeras familias en el lugar. Los primeros Shuar llegaron a Congüime, por el año 1975, dirigidos por Eduardo Juank Miik, definido como un luchador social, cuyo nombre lleva en la actualidad la Unidad Educativa Intercultural Bilingüe, tras su familia llegaron otras familias como los Samareño. El nombre de la comunidad se deriva de una castellanización de Kenkuim, palabra Shuar que significa “cañas de Guadúa”. Diego Arizaga es Presidente actual de Exploken (desde 2019) y clarifica lo siguiente:

32. CLARK Y BECKER (2007) p. 6.

33. SACHER (2015) p. 99.

34. SOLÍZ TORRES et al. (2012) p. 26; EXPLOKEN MINERA (2018). 
$\mathrm{Si}$, era una zona baldía donde ellos querían vivir alejados de lo que es de contaminaciones y todo eso. Zamora es conocido como un pueblo Shuar, una provincia nativa. Ya en ese entonces [los años 70] desde ahí se ha venido creando poblaciones, se ha venido entonces migrando más acá, hacia los rincones de la provincia, porque se iba poblando y ellos se iban haciendo una población grande. Ellos iban huyéndose a partes donde no haya muchos ruidos o mucha contaminación. Se iban yendo a lugares lejos como en esta zona llegaron, a la zona Congüime ${ }^{35}$.

Regresando al tema del extractivismo histórico, tradicionalmente, se han desarrollado actividades extractivas como la explotación petrolera en la Amazonía desde los 1950 y y con el boom petrolero entre los años 1972 y la actualidad, considerándose como la principal fuente económica y de desarrollo para los gobiernos de turno, siendo los territorios de los pueblos indígenas el principal campo de explotación y quienes han sufrido consecuencias negativas por los impactos socioambientales propios de la actividad. La resistencia histórica Shuar en contra de la extracción de recursos naturales por parte de actores ajenos se data principalmente de los años sesenta ${ }^{36}$.

Con respecto al extractivismo minero, es importante mencionar que, anteriormente al gobierno de Rafael Correa, la minería no era un sector económico estratégico $^{37}$. Es a partir de su gobierno cuando se inicia una nueva era extractivista, bajo el eslogan de efectuar "minería responsable" que permita dinamizar la economía nacional y cambiar la matriz productiva, incorporando sectores estratégicos "concebidos como aquellos que por su trascendencia y magnitud tienen decisiva influencia económica, social, política o ambiental, y que deberán orientarse al pleno desarrollo de los derechos y al interés social; precisando entre ellos a los recursos naturales no renovables" ${ }^{\prime 3}$.

El 18 de abril del 2008, la Asamblea Constituyente ecuatoriana expidió el Mandato Minero, lo que daría paso más adelante a la nueva Ley de Minería. Según Sacher y Acosta (2012), se trató de poner orden en la situación caótica que se vivía en el sector minero ecuatoriano. Además, cumpliendo con dicho mandato, el 31 de diciembre de 2009, se crea la ENAMI (Empresa Nacional Minera), institución del Estado establecida con el fin de regular la actividad extractiva del país, sin depender de inversión extranjera, sino por el contrario, proveer de financiamiento a pequeños proyectos

35. ARIZAGA, entrevista, Congüime, 10 de julio del 2019.

36. Ver también FERNÁNDEZ-SALVADOR (2018).

37. LATORRE TOMÁS (2012); LALANDER y MERIMAA (2018).

38. MINISTERIO DE MINERÍA (2016) p. 1. 
mineros y a mineros artesanales, haciendo énfasis en la mejora del manejo social y ambiental ${ }^{39}$.

La historia minera de explotación aluvial en Congüime tuvo sus inicios en 2004 con la empresa Terrígeno Gold Mine. El área que pretendían explotar correspondía a 410 ha, conformando la Concesión Minera ubicada dentro del territorio de la comunidad Shuar denominada Kenkuim. Según Kaymanta Consultores, durante este período de explotación legal se realizaba actividades como arranque de grava aluvial mineralizada, lavado de la grava aurífera, concentración gravimétrica del oro y posterior recuperación mediante amalgamación con mercurio ocasionalmente ${ }^{40}$. Posteriormente, y a consecuencia del Mandato Minero del año 20o8, la concesión es revertida al Estado ecuatoriano. Por lo tanto, la empresa Terrígeno GoldMine abandona la zona, provocando la llegada de mineros ilegales que explotaron el oro sin instancias de control y de forma indiscriminada, contaminando los recursos naturales y generando pasivos ambientales ${ }^{41}$. En este tiempo de la minería ilegal, las familias Shuar alquilaban sus terrenos a los mineros y recibieron un porcentaje de las ganancias. Asimismo, a nivel individual, una cantidad de hombres Shuar ofrecieron su fuerza laboral como jornaleros. Mediante la búsqueda de oro en las quebradas, podían extraer un gramo por día, lo que correspondía a aproximadamente 40 dólares a diario ${ }^{42}$.

Por otro lado, entre los Shuar de la comunidad, ya varios años antes de la formación de Exploken Minera habían comenzado con el proyecto de manejar la minería de una manera socio-ecológicamente responsable y de descontaminar el río y la tierra del mercurio. Como fue mencionado, los Shuar tenían experiencia de minería artesanal e ilegal. Pedro Juank, campesino Shuar quien ha representado a su comunidad como secretario, síndico y vice síndico, indica que los primeros lavadores de oro en Congüime lo realizaron de forma artesanal, por parte de los propios habitantes que se iban asentando en la zona, a finales de los años 70 e inicios de los años 80, lavaban el oro de forma esporádica, pero no representaba su sustento económico, pues vivían principalmente de su labor en el campo (pesca, caza y agricultura), además hace hincapié que la actividad minera como la conocemos ahora, donde se remueven grandes cantidades de tierra y se utiliza maquinaria pesada, fue introducida en la comunidad por los mestizos, que llegaron atraídos por el oro. Es decir, no es una actividad propia de los Shuar. Por lo tanto, posteriormente a la minería artesanal y para un mejor aprovechamiento del recurso, empieza una etapa de operación minera legal, por parte de

39. SACHER y ACOSTA (2012); SACHER (2015).

40. KAYMANTA CONSULTORES (2012).

41. MINISTERIO DEL AMBIENTE (2016).

42. EL COMERCIO (2010). 
Luis Alejandro Miranda, de origen colombiano, quien tenía la concesión de la zona, misma que fue revertida al Estado ecuatoriano luego del Mandato Minero, podría decirse que fue en este periodo en la que, por primera vez, se pudo observar la actividad extractiva en relativamente mayor escala, aún considerada pequeña minería ${ }^{43}$.

\section{El nacimiento de Exploken Minera}

Reconectando ahora a la política minera del gobierno de Rafael Correa, es importante ubicar a Congüime en el contexto de coyuntura política, económica y, evidentemente étnico-cultural y ambiental, con la profundización y ampliación constitucional de los derechos de la naturaleza y los pueblos indígenas ${ }^{44}$. En este contexto, el Estado decidió limpiar el territorio de Congüime (y otras localidades mineras) de la minería ilegal. Por décadas el Estado estuvo ausente en muchas zonas mineras, excepto por la presencia de militares que frecuentemente operaban ahí por intereses y beneficios particulares ${ }^{45}$.

Un hito importante se presenta en el año 2010, cuando el Estado finalmente desaloja a los mineros ilegales y artesanales en Congüime como medida de regulación de la actividad minera ${ }^{46}$, con la presencia de policías, militares y agentes de instituciones reguladoras (OBSA, 2018 b). Estas políticas estratégicas en Congüime jugaban dos roles fundamentales; por un lado, remediar la contaminación ocasionada por los mineros ilegales que invadieron un corto periodo con maquinaria pesada, ocasionando casi el $55.1 \%$ de daños ambientales en el territorio ${ }^{47}$, situación que afectó drásticamente a los recursos naturales y calidad de vida de las comunidades Shuar y de zonas aledañas. Por otro lado, el objetivo era también impulsar la explotación y redistribución de ganancias económicas hacia el Estado como se enfatiza en la estrategia nacional. Por esto, el Estado decide actuar a través de sus competencias de control ambiental y minero, prohibiendo a los ilegales las operaciones en la zona, como política de control y regulación de los daños ambientales ocasionados. La concesión minera del territorio se entregó a la Empresa Nacional Minera (ENAMI). El 25 de abril de 2011, otorgaron los títulos de las concesiones para minerales metálicos de las áreas que conforman los Proyectos Congüime I y Congüime II a la ENAMI ${ }^{48}$. Por tanto, la ENAMI siendo

43. JUANK, entrevista, Congüime, 11 de julio, 2019.

44. LALANDER (2014); LALANDER y MERIMAA (2018).

45. SOLÍZ TORRES et al. (2012) p. 10.

46. Ibid. p. 26.

47. MINISTERIO DEL AMBIENTE (2016) p. 6.

48. KAYMANTA CONSULTORES (2012). 
a partir de este momento la encargada de manejar las concesiones mineras de tales proyectos, debía restaurar los ecosistemas y compensar socioeconómicamente a la comunidad de Congüime por la afectación del flujo de beneficios a nivel de servicios ambientales y de salud.

Ya se había formado en 2011 la Asociación Kenkuim Kuri Nunka ${ }^{49}$, con 63 socios Shuar, para posteriormente poder lograr la concesión legalmente según los criterios establecidos en la legislación ecuatoriana ${ }^{50}$. Incluso, habían sugerido desde la asociación Shuar una estrategia para descontaminar el río y los terrenos de Congüime. Estos avances en la pequeña comunidad amazónica Shuar tuvieron eco nacional. El 12 de julio del 2012, el Presidente Rafael Correa expresó que la minería indígena de la comunidad Kenkuim-Kuri Nunka iría a "convertir a Congüime en una comunidad modelo... [y] que la minería Congüime será un ejemplo de desarrollo"51. No obstante, la Asociación Kenkuim Kuri Nunka no tuvo éxito en legalmente ser otorgada la concesión formal y consecuentemente tuvieron que establecer legalmente una empresa.

El 24 de mayo del 2014 se creó la Compañía Shuar Exploken Minera S.A., ${ }^{52}$ con representación de los 63 socios y todas las familias de Kenkuim. En este escenario, finalmente en el 2016, el gobierno previo varias consideraciones en la zona, como el desastre ambiental, las injusticias sociales de distribución de recursos, y las altas cifras de inversión económica por parte del Estado para remediar los sistemas ecológicos de los recursos hídricos y compensaciones sociales. Estratégicamente, ceden los derechos a la primera empresa minera conformada por los Shuar de Congüime, quienes asumen este desafío bajo los lineamientos ambientales establecidos por ENAMI ${ }^{53}$.

49. Se debe clarificar que Kuri Nunka no es un lugar. En el idioma Shuar, Kuri Nunka significa "Tierra llena de oro", por eso agregaron Kuri Nunka al nombre de la Asociación Shuar comunitaria. Kenkuim (nombre Shuar de Congüime) es la comunidad.

50. EXPLOKEN MINERA (2018). Ver también: LA HORA (2012); EL TELÉGRAFO (2012; 2014);

EL UNIVERSO (2012).

51. LA HORA (2012).

52. GOBERNACIÓN DE ZAMORA CHINCHIPE (2014); EXPLOKEN MINERA (2018).

53. Ver también: MINERÍA EN LÍNEA (2016). 


\section{Resultado y análisis: Dilemas, disputas y desafíos en la comunidad Shuar de Congüime}

\section{1 ¿Ser o no ser empresa minera comunitaria?}

Desde los planes iniciales de establecer una minería comunitaria hubo diferentes posiciones en cuanto al escenario de ser una empresa minera comunitaria. El primer dilema fue, por supuesto, la decisión misma de dedicarse o no a la actividad minera. En el lado positivo, la minería artesanal se había integrado en la vida cultural del Shuar en diferentes localidades de la Amazonía y un mayor compromiso probablemente produciría ingresos importantes para la comunidad. En el lado negativo, no fue una decisión fácil entrar en el mundo del negocio minero, con las asociaciones al "extractivismo", considerado como el enemigo y blanco principal en las luchas de la resistencia indígena amazónica y andina.

Ya durante el primer tiempo de existencia de Exploken Minera, e incluso anteriormente a su establecimiento legal, hubo tensiones y divisiones en la comunidad al respecto. Como se declaró en la sección anterior, los socios del Centro Shuar Kenkuim Kuri Nunka se habían constituido con la llegada de la compañía Estatal ENAMI, en un inicio con 63 socios Shuar, con la finalidad de poder realizar la actividad minera. Pero, este convenio fracasó, por lo que al poco tiempo se creó la compañía Exploken Minera S.A. y en este proceso inicial, pronto se produjo una reducción de socios a los 26 miembros que permanecen hasta la actualidad. Ramiro Enríquez, ingeniero principal de Exploken desde el inicio, expresa que la reducción de socios se debió a:

...la mala administración de ese entonces, de ENAMI, prácticamente quebró por lo que no todos pasaron a ser parte de Exploken Minera. Algunos se quedaron en el camino, dijeron: "No, a mí no me interesa eso, allá vean los que quieren y nosotros nos hacemos a un lado", y se quedaron únicamente $26 \operatorname{socios}^{54}$.

De igual forma la socia y trabajadora de Exploken, Tania Tanduama, manifiesta que los 26 socios que se mantienen como parte de Exploken son quienes estaban de acuerdo con la actividad minera y la creación de la empresa, además señala, que quienes desertaron en aquella época están arrepentidos y que incluso expresan que no fueron tomados en cuenta, pero ella sostiene que los 37 socios que se retiraron fue de forma voluntaria.

54. ENRÍQUEZ, entrevista, Congüime, 11 de febrero, 2019. 
Solo nosotros nos conformamos, los 26 socios todas las personas que estaban, que querían que hayga la minería. Ya entonces, hay otras personas que no quisieron que hayga la minería, o sea, no querían. Entonces, ya se dividieron. La gente, entonces, ellos como que están arrepentidos como que nosotros no les hemos tomado en cuenta, porque había otra compañía que se llamaba la Kuri Nunka. Entonces ahí toditos los socios de la comunidad fuimos incluidos. Otros renunciaron de esa compañía. No quisieron que esta compañía siga. Entonces ya con las personas que estaban interesadas ya somos los 26 socios. Ya entonces ellos están arrepentidos. Dicen que no perciben, que no les han tomado en cuenta. No es que nosotros no les hemos tomado en cuenta, sino que ellos renunciaron, no querían ${ }^{55}$.

\subsection{Minería comunitaria y la cultura Shuar}

La minería nada tiene que ver con la pérdida de la identidad, la minería es una cosa, la aculturalización es otra ${ }^{56}$.

Como Shuar tenemos varias costumbres, la pesca, la cacería, que eso ya viene descendencia de nuestros padres... Mi padre me enseñó a comer lo que es comestible y lo que no es comestible, qué plantas y frutales del campo son para comer y para no comer, es decir, que se consume esas plantas y se saca un veneno. Más antes se utilizaba como un veneno para matar, para cazar con esos mismos con las sayetas. Las sayetas llamamos las flechas. Entonces, con eso lo mataban ellos al animal, o mataban al enemigo, al tigre o a las personas ${ }^{57}$.

Los antepasados no hacían minería, eso la trajeron los hermanos de otros lugares, nuestros abuelos no sabían del oro, no es nuestra cultura... La minería no es parte de la cultura, pero la realizamos por necesidad, por la falta de recursos ${ }^{58}$.

Consecuentemente, hay diferentes narrativas del impacto de la minería en la Cultura Shuar entre los comuneros Shuar. Se contrastan también en las declaraciones de Fausto Juank y Blanca Ankuash abajo:

55. TANDUAMA, entrevista, Congüime, 11 de febrero, 2019.

56. PIRUCH ATSAMP, entrevista, Congüime, 19 de diciembre, 2019.

57. ANKUASH QUIZHPE, entrevista, Congüime, 13 de febrero, 2019.

58. JUANK, entrevista, Congüime 19 de diciembre, 2019. 
Nuestros abuelos no compraban en la ciudad, todo lo conseguían del campo, salían de cacería y traían la guanta y el armadillo, ahora es prohibido ${ }^{59}$.

Nosotros no nos descuidamos lo que es el campo, es decir, sembrar la yuca, el plátano, los ganados. Eso no nos descuidamos y seguimos con lo mismo. Nosotros que trabajamos en la minería, yo dejo de criar una gallina, un ganado. ¡No! Yo tengo acá mis animales, mantengo aquí la gente, el trabajo y en mi finca. Ya que esa persona no puede trabajar aquí exactamente, pero doy con ese dinero que yo gano de mi sueldo, pago a un trabajador para que este trabajador me dé sembrando pasto. Ya entonces, estoy dando fuente de trabajo yo. Yo hago así y varios compañeros que trabajamos aquí hacen así, con la siembra de yuca ${ }^{60}$.

Por su parte, el líder cofundador de Exploken, Alipio Wajari se refiere a las particularidades históricas y socioculturales de los Shuar de Kenkuim en relación a la minería:

Esta comunidad ha sido, desde el nacimiento, desde que nacieron, han sido mineros. Yo por eso a esta comunidad le apoyé con énfasis, le dije: "Aquí va a ser una compañía por primera vez en la historia en el Ecuador y en el mundo, un pueblo Shuar con una compañía [minera] chica"61.

En la cita de arriba y en muchas de nuestras conversaciones con los Shuar de Congüime, se enfatiza fuertemente el valor de que sea Shuar la minería. Esa es una gran diferencia, en comparación con la situación anterior de la minería ilegal, cuando los Shuar alquilaban sus tierras a los mineros y, también, prestaban su servicio laboral como jornaleros.

Bueno, para la cultura Shuar por una parte es bueno hacer minería legalmente... Por otra parte, a veces como que se dispersa en varias personas y conflictos por eso, por medición de terrenos, por tener una minería aquí legal que haya tenido la comunidad...O sea, [los Shuar] están muy orgullosos por hacer algo bonito que estamos haciendo, aprendiendo y en eso seguiremos aprendiendo más ya para poder seguir haciendo una minería ${ }^{62}$.

\section{Ibid.}

60. ANKUASH QUIZHPE, entrevista, Congüime, 13 de febrero de 2019.

61. WAJARI, entrevista, Congüime, 12 de febrero del 2019.

62. ARIZAGA, entrevista, Congüime, 10 de julio del 2019. 
Esta lógica también se conecta al argumento de ecología política de Escobar (2006) sobre la importancia de las tradiciones, ontologías, epistemologías y sistemas organizativos culturalmente definidos a nivel local-comunitario. Sólo el hecho de ser comunitaria la empresa minera indígena, conecta directamente a la importancia de la solidaridad colectiva como pueblo Shuar. Por ende, se enfatiza este valor simbólico específico del territorio y la territorialidad para los Shuar. Desde esa perspectiva del valor étnico-cultural-territorial y - considerando las décadas que han vivido ahí con la minería ilegal y otros mineros privados - el hecho de establecer su propia empresa minera de responsabilidad socioecológica, significa un logro enorme, en comparación con la situación anterior cuando eran víctimas del extractivismo ilegal y privado y con graves implicaciones ambientales y sociales. Es decir, ahora desde la legalidad los Shuar de Congüime tienen mejor control territorial, y además están en mejores condiciones para proteger el ambiente y defender su cultura comunitaria ${ }^{63}$.

No obstante, si bien la minería indígena generalmente está generando orgullo local, hay preocupación en la comunidad sobre las viejas habilidades y tradiciones que arriesgan olvidarse. Por lo tanto, se perdería otro tipo de orgullo, arraigado en la cultura originaria:

Ya no estamos haciendo la cacería. Como ya no hay como hacer cacería, porque hay las leyes que nos prohíben. Encima de eso, nosotros no tenemos como pueblo Shuar ningún dirigente de la comunidad que se ha atrevido a pedir permiso al MAE [Ministerio del Ambiente] para decir que nosotros como Shuar vamos a vivir como Shuar, de caza y pesca. También estamos ya desmontando todo. Entonces, ya no hay ni qué cazar, ni qué pescar, ni lo referente a la fruta ${ }^{64}$.

Las autoridades no se preocupan por los hermanos indígenas. Por eso deben hacer minería para dar estudio a nuestros hijos, para mantenerse. De la minería se sustenta a la familia, incluso al país le ingresa más recursos ${ }^{65}$.

Según esta segunda declaración pragmática se justifica la minería desde la perspectiva socioeconómica. Para muchas familias Shuar, Exploken ofrece empleo ya que no hay otras opciones viables y las condiciones para la caza, pesca y agricultura ya se habían deteriorado tanto como consecuencia de la minería anterior ilegal y privada.

63. Evidentemente, al mismo tiempo, desde esta lógica subjetiva es importante enfatizar que la interpretación de cómo se defienden estos valores ecológicos y culturales, puede variar entre y dentro de los actores e igualmente por parte de los investigadores.

64. WAJARI, entrevista-taller, Congüime, 21 de febrero de 2019.

65. JUANK, entrevista, Congüime 19 de diciembre, 2019. 
Eso nace por [cuestiones de] la economía y por obtener recursos para sustentar a la familia de cada uno...La iniciativa surgió de aquí mismo, de la comunidad, que la comunidad haga minería ${ }^{66}$.

La gente ya estaba familiarizada con la minería. Entonces, acá fue fácil continuar... la gente lo tomó con buenos ojos, obviamente, porque acá se ha generado bastantes ingresos para la comunidad misma y lo que decía al inicio, lo bueno es que el dinero se queda acá mismo, porque todos son de acá ${ }^{67}$.

No obstante, algunos comuneros expresan que las condiciones económicas eran mejores anteriormente con los ilegales - cuando podían ganar hasta 40 dólares por día- que en la época actual de Exploken con sus términos de salario básico ${ }^{68}$.

\subsection{Responsabilidad socioecológica}

Otro dilema surgió particularmente de las preocupaciones socioecológicas y de si era posible alcanzar otro tipo de minería, más ecológicamente responsable. Un objetivo central de Exploken Minera es el de mejorar las condiciones de vida de la población local en el ámbito social, económico, ambiental y cultural, e incluso trabaja para proveer bienestar para toda la población de Congüime. En cuanto a la responsabilidad socio-ecológica, en sus estatutos Exploken Minera declara que su misión:

...está orientada a la explotación técnica y racional de los recursos mineros con alto sentido de responsabilidad social y ambiental... [y con la visión de] ser una empresa líder en minería comunitaria reconocida por su excelencia y posicionada a nivel nacional entre las principales empresas de pequeña minería del país ${ }^{69}$.

Las percepciones comunes de la población local es que la minería comunitaria debe considerarse verde y responsable y que no constituye una amenaza para las otras actividades de los Shuar. El presidente actual de Exploken, Diego Arizaga, se pronuncia completamente en contra de la contaminación:

Y por eso, desde ese entonces, al Shuar no le ha gustado lo que son las contaminaciones, las cosas hechas con químicos, ya todito. Eso entonces, en la alimentación se han criado con lo que es la agricultura de la zona, como es también de la pesca y la caza. En eso se han venido manteniendo

66. ARIZAGA, entrevista, Congüime, 10 de julio del 2019.

67. ENRÍQUEZ, entrevista, Congüime, 11 de febrero del 2019.

68. Entrevistas anónimas en Congüime, febrero-julio del 2019.

69. EXPLOKEN MINERA (2018). 
ellos, no les ha gustado la contaminación...Aquí no se está utilizando lo que son químicos, o mercurio. Bueno, eso más se utilizaba más antes acá en la minería ilegal. Que ese mercurio, de aquí, digamos, es eso de derrame, de combustibles, de aceites, todo eso, se está cuidando y se está manteniendo para que no se contamine ${ }^{70}$.

Declaraciones parecidas se escuchan también entre los comuneros Shuar que no tienen vínculos directos con Exploken, en palabras de Ramón Puatza y Alberto Orellana:

Aquí la minería en Congüime es que trabajamos por parte de la comunidad. Un poco como la comunidad Congüime Shuar trabajamos legalmente, se puede decir y, con materiales que no contaminan. No contaminamos ${ }^{71}$.

Al mismo tiempo, se expresa consciencia sobre los riesgos de distorsionar el ecosistema con las actividades mineras y que siempre pueden causar impactos por lo menos temporales en el ambiente:

Nosotros somos conscientes que si movemos las tierras destruimos, pero somos conscientes que sí tenemos que reforestar, sembrar las plantas y cuidarlos, porque eso es importante, incluso ya ahora ya creo que los árboles de guabas ya están bien grandes, pero nosotros como conocemos que planta puede crecer aquí, que tipo de árboles son del sector, no podemos traer unas plantas de otros lugares ${ }^{72}$.

Sin embargo, la conciencia ecológica y la descontaminación de la empresa comunitaria conllevaron costos económicos muy significativos, por ejemplo, para regular los pasivos ambientales, como clarifica el ingeniero principal de Exploken:

El costo que ha involucrado el tema de pasivos ambientales nos tocó asumirla nosotros cien por ciento. Para el tema de remediación de pasivos ni siquiera ENAMI como exconcesionaria nos ayudó con las auditorías que tenía por obligación hacerlas no son capaces de hacerlas...nos tocó a nosotros. Desde la primera auditoría que tenía ya cuatro años de vencimiento nos tocó hacerla nosotros...ese ha sido quizá el costo más grande que le ha tocado a Exploken Minera asumir el tema ambiental ${ }^{73}$.

70. ARIZAGA, entrevista, Congüime, 10 de julio del 2019.

71. PUATZA y ORELLANA, entrevista/taller, Congüime, 21 de febrero de 2019.

72. ANKUASH QUIZHPE, entrevista, Congüime, 13 de febrero, 2019.

73. ENRÍQUEZ, entrevista, Congüime, 10 de julio de 2019. 
Pero hay quienes son más críticos con la minería local desde las perspectivas ecológica y sociocultural. Algunos críticos que Exploken secretamente (de noche) utilizan el mercurio para procesar el oro, pero estas acusaciones se rechazan categóricamente desde la directiva de Exploken y no se han podido evidenciar ninguna prueba de tal uso contaminador. Lo que sí es cierto, por otro lado, es que partes de la contaminación en Congüime se deriva de la minería en la localidad circunvecina de Chinapintza (más arriba de Congüime) donde no tienen los mismos criterios de responsabilidad socio-ecológica ${ }^{74}$.

Redondeando esta sección, y reconectando al tema de la consciencia socioecológica de los indígenas y el discurso sobre las relaciones armoniosas entre seres humanos y la naturaleza, indudablemente un componente central en la autoidentificación Shuar, si bien es cierto que la mayoría de los actores en Congüime no hablan de estas relaciones en términos de Sumak Kawsay/Buen-vivir. Pero, sus declaraciones expresan la misma lógica considerando las relaciones humanas con el ambiente y los valores ecológicos, culturales y económicos. Al mismo tiempo, se puede reflexionar sobre los posicionamientos acerca de la empresa minera como una arena de lucha discursiva y las tensiones y colisiones existen tanto a nivel colectivo de los Shuar, como a nivel de cada individuo, el resultado de los eternos choques entre discursos alrededor de los valores culturales, ecológicos y económicos.

\subsection{Los impactos de Exploken en la interacción social comunitaria}

Otro dilema, o más bien un desafío, tenía que ver con la cuestión de cómo garantizar que la unidad de la comunidad local no se vea comprometida debido al hecho de que los comuneros tenían opiniones contradictorias sobre la participación en las actividades mineras. En otras palabras, cómo mantener la necesaria cooperación comunitaria si no hay consenso sobre el elemento crucial que afecta a la vida comunitaria. ¿El establecimiento de la empresa, de hecho, representa una amenaza para la toma de decisiones colectivas y orientada al consenso local?

Varios de los dilemas, disputas y desafíos tratan del poder económico local y el uso y redistribución de los réditos obtenidos. Hasta cierto grado, Exploken Minera asumió la función de gobierno local, con la misión de proveer bienestar social en la comunidad. Por ejemplo, ha financiado computadoras, material e infraestructura del colegio comunitario. La comunidad, por su parte, debe identificar y presentar sus prioridades y necesidades en forma de proyectos, los cuales podrán financiarse por Exploken.

74. Entrevistas anónimas, Congüime, febrero-diciembre, 2019. Ver también: OBSA (2012); SÁNCHEZ-VÁSQUEZ et al. (2016). 
Con la comunidad acá, pues, nosotros tenemos buenas relaciones con la comunidad. Nosotros hemos manejado bien en ese sentido. De hecho, nosotros también tenemos un aporte a la comunidad, que otras empresas no lo hacen así directamente a la comunidad. Este aporte lo estamos ejecutando a través de proyectos ${ }^{75}$.

En la cultura Shuar, el máximo vocero de la comunidad es el síndico ${ }^{76}$. En la práctica sociocultural, el síndico puede colaborar, aprobar, criticar o rechazar las actividades o incluso cuestionar la existencia de la minería comunitaria Shuar. Por un lado, la comunidad Kenkuim es la dueña de Exploken. Por otro lado, Exploken es socio del Estado ecuatoriano a través de la concesión y la comunidad funciona como agente de vigilancia de las decisiones y operaciones de la empresa.

Fausto Juank señala que, según su parecer, aunque la minería ha dejado importantes recursos económicos a la comunidad y que les permitirá realizar proyectos en favor de todos, así mismo manifiesta que lastimosamente la minería no benefició a toda la población y que hubo mucha gente que no aprovechó.

La minería afecta bastante, la gente solo ha llegado a utilizar al pueblo, para beneficio personal... No se benefician todos los socios de la comunidad con la minería, ya que ésta no abarca a todas las familias, la gente de afuera es la que más ha sacado provecho. Otra desventaja es que las oportunidades de trabajo no han sido para todos y que los trabajos con mejor paga, eran para personas que venían de afuera ${ }^{77}$.

Juank comentaba que todos los ingresos no quedan en la comunidad y que la minería también beneficia a agentes externos. En este sentido es oportuno clarificar la particularidad fundamental de la relación entre Exploken y los "operadores-inversionistas". Considerando que ni la comunidad, ni la Exploken Minera tenía fondos

75. ENRÍQUEZ, entrevista, Congüime, 10 de julio de 2019.

76. El Síndico es quien representa la comunidad ante las autoridades estatales y es elegido por sus miembros mediante una asamblea comunitaria la cual está presidida por un presidente. La función del síndico es dar a conocer las necesidades que existen en su centro comunitario, así como ayudar a resolver los conflictos internos. En cuanto a la administración de las regalías mineras su rol es importante ya que define de qué forma se realiza la entrega de estas en el centro Shuar, ya sea mediante la acumulación para invertir en la ejecución de proyectos, o la repartición en proporciones económicas a cada familia, según sean las prioridades de inversión del centro comunitario. Retrospectivamente se resaltan dos tendencias en este sentido; primero, repartir proporcionalmente estas regalías a cada familia, y segundo, usar los ingresos para proyectos a corto, mediano o largo plazo para invertir en el futuro de la comunidad (entrevistas en Congüime, febrero-julio, 2019).

77. JUANK, entrevista, Congüime 19 de diciembre, 2019. 
o maquinaria para iniciar las operaciones mineras, se estableció en 2016 un sistema con empresas socias, los operadores o inversionistas, que invierten en Exploken con su dinero y maquinaria en la extracción de oro y reciben su parte de las ganancias. No obstante, Exploken mantiene el control de contratación y operación en términos de responsabilidad social y ecológica. Según la ley, el 80 \% de los empleados deben ser de Congüime y hasta el $20 \%$ pueden ser de afuera. A mediados de 2019, cuatro empresas operadoras estaban operando activamente en los frentes de Exploken en Congüime, lo que representa una reducción, considerando que antes había más operadores, según clarificaciones de Maryuri Wampash, secretaria de Exploken ${ }^{78}$.

El síndico Fausto Juank reflexiona que efectivamente la comunidad ha dependido económicamente de la minería. Sí existen familias que viven del campo, pero la mayoría trabaja y vive de la minería, además que de la gente que se benefició de la actividad extractiva, no todos aprovecharon, y que les ha tocado volver al campo ${ }^{79}$. Debemos repetir y subrayar, no obstante, que muchos de los problemas locales tratados en este artículo, incluso los dilemas, disputas y desafíos experimentados por los Shuar en la actualidad, estaban presentes en la comunidad ya antes de la formación de Exploken.

\subsection{El protagonismo de las mujeres Shuar}

Es la única empresa que es Shuar, que está conformada de mujeres, hay más mujeres que varones. Así mismo en el campo de trabajo igual hay mujeres. Asimismo, yo como presidenta, también como mujer. Nosotros como mujeres tenemos, yo al menos, tengo el dicho que cuando una mujer se propone algo es porque lo va a hacer, y si no lo va a hacer no lo hace, no se compromete $^{80}$.

Estas palabras de Blanca Ankuash Quizhpe, presidenta de Exploken entre 2016 y 2019, enfatizan la fuerte presencia de las mujeres en Exploken Minera, tanto en la directiva como de las trabajadoras, que asimismo ha conllevado cambios significativos en la comunidad. Las mujeres Shuar que trabajan en la minería de Exploken tienen ahora un mayor grado de autoestima, un sueldo decente, y es más independiente en la comunidad. En comparación con las épocas anteriores, las mujeres ahora se han establecido como trabajadoras en un sector donde anteriormente trabajaban casi exclusivamente hombres.

78. WAMPASH, entrevista, Congüime, 18 de julio, 2019. Ver también: EXPLOKEN MINERA (2018).

79. JUANK, entrevista, Congüime 19 de diciembre, 2019.

80. ANKUASH QUIZHPE, entrevista, Congüime, 13 de febrero de 2019. 
Blanca Ankuash también subraya la importancia del contexto político, y del Presidente Correa, para el fortalecimiento relativo de la mujer en la sociedad ecuatoriana.

Nos dijeron que si nos podían ayudar a la capacitación que nosotros solicitamos cuando era Rafael Correa presidente. Yo no soy mal agradecida de él, porque en la época de él por lo menos nos hicieron valer a las mujeres. Desde ahí creo que muchas mujeres están trabajando y en varias instituciones. Mucho más antes no nos daban importancia a las mujeres, como que les discriminaban, que les daban poca importancia. Pero, ahora veo que las mujeres también estamos liderando en varias instituciones y demostrando que sí somos capaces, no solamente en la casa, en el hogar. No, sí podemos hacer en campo de trabajo, en lo ambiental, en diferentes instituciones ${ }^{81}$.

El ingeniero de Exploken, Ramiro Enríquez, ofrece su interpretación:

Claro que sí, de hecho la participación de la mujer podría haber sido aún mayor si es que hubiéramos contado con el respaldo de los operadores en un mayor grado porque las pocas mujeres que trabajan ha sido realmente por pedido nuestro, por pedido de acá de la compañía que es la que actúa porque ellos todavía tienen esa percepción o ese tipo de estereotipos todavía de que la mujer no puede trabajar, cuando realmente ellas han demostrado que la mujer también está en capacidad de hacer el trabajo, los mismos trabajos de chofer o en el frente. Y, gracias a ellas se ha logrado sacar la gestión de acá, sobre todo de Silvia [Blanca Ankuash] que ha sido la fundamental en ese sentido de proponer que vayan también a los frentes a trabajar. Gracias a eso se ha logrado que algunas mujeres de acá, algunas que son madres solteras, por ejemplo, que no tenían esposo. Muchas de ellas están todavía trabajando allá, entonces, otras también ya han salido, pero si se ha logrado insertarlas a ellas también en el proyecto como obreras, y de aquí prácticamente a nosotros nos acompañan. Es como la mitad prácticamente, son mujeres... Cuando teníamos el fuerte de la cantidad de trabajadores acá, la mitad de ellas eran mujeres ${ }^{82}$.

Hay, sin embargo, otras voces más críticas al respecto, que opinan que esta liberación de la mujer Shuar en los años más recientes ha contribuido a un aumento significativo de divorcios en Congüime. En varias ocasiones durante el trabajo de campo escuchamos estas interpretaciones, como una de las consecuencias de la minería comunitaria y la gran cantidad de mujeres trabajadoras. Entre los Shuar que se

81. ANKUASH QUIZHPE, entrevista, Congüime, 13 de febrero de 2019.

82. ENRÍQUEZ, entrevista, Congüime, 10 de julio de 2019. 
posicionan en contra del proyecto Exploken, un líder joven opina que la minería ha perjudicado a la vida en general y, sobre el tema de las relaciones de género, considera que "la gente se casa y se separa, incluso buscan otra mujer y forman un nuevo hogar, abandonando a su anterior familia" ${ }^{13}$. En palabras de otro líder de la comunidad:

Y si no puede justificarse diciendo que estoy haciendo buena minería por dar trabajo a la mujer y también destruyendo a los hogares en la parte social. ¿Está bien? $\mathrm{Ni}$ a usted le va a gustar que su esposa se vaya, disculpe, con hombres varones, que vaya allá y usted durmiendo ${ }^{84}$.

Consecuentemente, hay interpretaciones divididas sobre el empoderamiento de las mujeres, y culturalmente estos procesos de cambio tienden a ser difíciles, lentos y graduales. Indudablemente, no obstante, el caso de Congüime se distingue rotundamente al contrastarse con la situación típica del sector extractivista, en la cual se fortifican los roles y estereotipos de "hombre-trabajador-proveedor/mujer-ama de casa-cuidadora" ${ }^{85}$.

\subsection{Desafíos pendientes: Se acaba el oro en Congüime}

La minería no es estable. Tarde o temprano se acaba. Pero, nosotros como dirigentes, también soy dirigente de aquí de la comunidad, soy el [vice-] síndico. Trataremos de rescatar nuestra cultura, lo que es el Shuar ${ }^{86}$.

Yo diría que la gente está aquí por la minería. Pero, llegando a pensar, pues, ya la minería se está acabando y de ahí yo me pongo a pensar: ¿Qué sería más después, cuando esa minería se acabe, a dónde? Es mi preocupación, porque yo vivo de eso, de la minería. Porque yo no tengo terreno, ya como quiera, con mi trabajo que estoy aquí, tengo mi casita, tengo mi lote ${ }^{87}$.

Las palabras de Ismael Wampash Saraguro y Tania Tanduama reflejan preocupación. Según el síndico Fausto Juank, los jóvenes Shuar están conscientes de que la minería en Congüime es simplemente temporal. Con respecto a la pérdida del trabajo del campo, expresando que los que trabajaban en el campo se fueron a trabajar en mi-

83. Hombre Shuar anónimo X, Congüime 19 de diciembre, 2019.

84. Hombre Shuar anónimo Y, entrevista, Congüime, 11 de julio, 2019.

85. SVAMPA (2019) p. 78.

86. WAMPASH SARAGURO, taller-entrevista, Congüime, 21 de febrero de 2019.

87. TANDUAMA, entrevista, Congüime, 11 de febrero del 2019. 
nería, así mismo considera que la juventud dejó de estudiar para dedicarse a trabajar en la minería, sin embargo, señaló que en la actualidad se ha evidenciado un incremento de jóvenes que volvieron a estudiar, porque son conscientes que la minería se está acabando. Sugiere que podrían producirse diversificaciones del mercado laboral local. Se tiene ya un proyecto de ganado con el apoyo de Exploken para incentivar nuevamente el trabajo en el campo. Así mismo, gracias a un convenio entre la junta parroquial de Nuevo Quito y la comunidad Shuar de Kenkuim, se han entregado pollos a las familias Shuar para que los reproduzcan y los puedan vender. Es decir, están buscando alternativas económicas una vez terminada la minería. Fausto Juank menciona que se tiene proyectos para ya no depender de la minería, se busca recursos económicos alternativos, como la ganadería y crianza de pollos ${ }^{88}$. Según el director del colegio de Congüime, Herminio Anibal Piruch Atsamp: "la comunidad tendrá que volver al pasado... a mirar las fincas, no queda más”. Para él, la migración de los Shuar para las ciudades no es una opción:

Algunos que se corrieron a la ciudad, se terminaron lo de la minería en unos añitos, otros venderán y otra vez volverán... El Shuar no es para que esté yendo a la ciudad, ni viva ahí, ni acostumbrarse. ¡No!, Él es del campo, no es para que viva allá en la ciudad. Nosotros como Shuar estamos acostumbrados al campo, manejamos bien lo que es del campo. Los compas mestizos interculturales se manejan allá porque son de ahí, saben sobrevivir. Nosotros sobrevivimos aquís ${ }^{89}$.

Asimismo, los representantes de Exploken mencionaron que están explorando las posibilidades de "exportar" su modelo minero y solicitar la concesión para otras localidades. Por supuesto, en tal caso el grupo de Exploken se verían como externo, es decir, no perteneciendo a la comunidad, lo que implicaría un contrato entre Exploken y la comunidad. En palabras de Blanca Ankuash Quizhpe, protagonista de Exploken desde el inicio, las experiencias han sido sobre todo positivas:

Ya estamos en la época de cierre y para mí ha sido una experiencia bien bonita aprender y lo que yo sé lo que me ha enseñado mi padre también, es compartir con las personas, con las autoridades, tanto como es la comida de lo que se come uno y lo que hay aquí, y que se puede vivir bien y ser feliz, compartiendo conocimientos, ideas y las costumbres nuestras de lo que somos ${ }^{90}$.

88. JUANK, entrevista, Congüime 19 de diciembre, 2019.

89. PIRUCH ATSAMP, entrevista, Congüime, 19 de diciembre, 2019.

90. ANKUASH QUIZHPE, entrevista, 13 de febrero de 2019. 
Redondeando este artículo, es oportuno reteorizar un poco el dilema de la minería responsable desde abajo de las comunidades indígenas. En comparación con otros contextos extractivistas en territorio indígena, en el caso de Congüime y Exploken Minera, lo que estaba en juego no era sacrificar el ambiente o la Pachamama, sino recuperarla y al mismo tiempo seguir con la minería, pero como empresa comunitaria Shuar, y minimizar el impacto ambiental y sociocultural. Más bien, consecuentemente, se trataba de reemplazar un tipo de minería destructiva con otro modelo minero caracterizado por responsabilidad socio-ecológica. Reconectando a las lógicas de ecología política, justicia socioambiental y el postdesarrollo, y específicamente hablando de los valores comunitarios colectivos como pueblo Shuar, se debe re-enfatizar el valor simbólico y cultural del territorio y la territorialidad. Comparando con la situación previa en la cual eran víctimas del extractivismo ilegal y privado, el hecho de ser comunitaria la empresa minera indígena, los Shuar de Congüime están en mejores condiciones para proteger el ambiente y defender su cultura.

\section{Conclusiones y reflexiones finales}

En este artículo hemos analizado las experiencias y los desafíos, disputas y dilemas experimentados por los Shuar de Congüime con su propia minería comunitaria. ¿Qué está cambiando en la minería para encajar en la tradición Shuar? Se han enfatizado los principios de responsabilidad ambiental y la distribución socioeconómica solidaria, en términos de más colectivismo y menos individualismo, especialmente en comparación con la época de la minería ilegal cuando los Shuar trabajaban como jornaleros. Lo más importante, sin embargo, no es que la minería en sí fortalezca la tradición Shuar, ya que ésta también contemporáneamente depende de los fundamentos socioeconómicos, y la minería ha sido un incentivo para fortalecer a la comunidad local socioeconómicamente, por lo tanto, en este sentido también fortificando las condiciones para la supervivencia de la cultura local. Además, es importante reconectar con nuestro razonamiento sobre la adaptación con la shuarización de la minería local.

Con respecto a las transformaciones de las estructuras locales de poder, se han identificado varias relaciones socioculturales que se han cambiado, no solamente la mera presencia de la empresa Shuar como el nuevo patrón de la comunidad, dirigida simultáneamente por las lógicas del mercado y las de la solidaridad comunitaria, expresándose en tensiones en los campos de las relaciones empresa-comunidad, entre socios y no-socios, entre generaciones, y, especialmente, entre hombres y mujeres. Para ejemplificar el dilema generacional, existe un sueño Shuar de la sociedad ideal, con las posibilidades de vivir de la caza y la pesca, pero también sobre las condiciones de vida de los jóvenes y sus posibilidades de estudiar para de tal manera fortalecer a la cultura. La minería local debe verse desde esta perspectiva, parcialmente como una adaptación realista frente al capitalismo ilegal y transnacional penetrante, en parte 
una manera de implementar esta alineación con los signos Shuar, mediante el sueño de ser capaces de recrear la comunidad tradicional Shuar a largo plazo, considerando también las preocupaciones sobre la terminación de Exploken Minera ya que se está acabando el oro en la zona.

Otro resultado importante del estudio es que el proyecto Exploken ha contribuido a las alteraciones en las relaciones de género. Una mayoría sostiene que la nueva situación ha permitido a las mujeres avanzar en sus posiciones en el mercado laboral local. Algunos rinden homenaje a este desarrollo, argumentando que ha ayudado a combatir los estereotipos basados en el género. Otros están preocupados, argumentando que ha contribuido a debilitar la unidad de las familias. Indiscutiblemente, sin embargo, el empoderamiento socioeconómico femenino es otro elemento que distingue a Congüime de las situaciones típicas del sector extractivista.

Hemos interpretado este caso como una variante de las utopías reales, como una mezcla entre adaptación y resistencia. La minería indígena puede parecer una contradicción de términos, pero también puede ser percibida como el resultado híbrido típico de la supervivencia, tanto adaptación como resistencia desde abajo. Por supuesto, como todos compromisos el proyecto presenta sus relativos defectos, limitaciones e imperfecciones. Es decir, en este caso se trata de la adaptación y la resistencia en contra de la amenaza e intrusión del capitalismo local, nacional, transnacional (e ilegal) y la devastación de su hábitat sociocultural y ambiental. La propuesta minera Shuar, en este sentido, se resalta como una variante comunitaria y responsable, aunque todavía siendo minería, pero minimizando los impactos sociales y ecológicos.

Exploken es un ejemplo de tal actividad económica a pequeña escala que -al menos en comparación con la minería ilegal anterior y el extractivismo transnacional circundante- opera de acuerdo con la sostenibilidad ecológica. A pesar de ser formalmente una empresa minera, es un proyecto anti-extractivista. Como subrayan varios de los entrevistados, siendo Shuar y comunitario el proyecto de Exploken contribuyó a un creciente sentido de orgullo a nivel local. La medida en que el compromiso minero impone o debilita las tradiciones Shuar es discutida entre la población local, y probablemente más entre los intelectuales y activistas que alimentan una comprensión más ideal de la indigeneidad. Sin embargo, se puede adoptar una interpretación más positiva al apartarse del punto de vista de que los indígenas siempre defienden su cultura combinando resistencia y adaptación. Además, una defensa de la cultura local requiere incentivos socioeconómicos. Aunque las opiniones difieren con respecto a la distribución comunal igualitaria de los ingresos mineros, Exploken ha tenido un efecto socioeconómico generalmente positivo para Congüime.

Si bien es cierto que la minería comunitaria de Congüime hasta cierto grado podría interpretarse como un compromiso con el capitalismo global y el mercado de oro, y a pesar de las complicaciones y disputas emergentes que se han mencionado en 
el artículo, podemos enfatizar que nuestro caso constituye un aporte de una opción dentro de las lógicas críticas de la ecología política, el post-desarrollismo y según los argumentos de la construcción pragmática de utopías reales. Con el fortalecimiento relativo de la comunidad Shuar vis-a-vis las empresas transnacionales y el Estado extractivista, y considerando que se trata de una experiencia en pequeña escala, con su misión de responsabilidad socioecológica, indudablemente puede interpretarse como una experiencia valiosa y que constituye un paso - o por lo menos una indicación muy importante - hacia otro modelo de economía y ecología política.

\section{Agradecimientos}

Los autores quieren agradecer profundamente a los actores protagonistas que generosamente aportaron a la investigación, especialmente a Silvia Ankuash, Alipio Wajari, Ramiro Enríquez, la familia de Pedro Juank y Fausto Juank, Diego Arizaga, Maryuri Wampash, Yulie y todos de Exploken Minera y la comunidad Shuar de Congüime. Asimismo, queremos reconocer la importancia del financiamiento de las actividades investigativas de STINT (Fundación sueca para la cooperación internacional en investigación y educación superior), FORMAS (Consejo Sueco de Investigación para el Desarrollo Sostenible), la Universidad Técnica Particular de Loja, Ecuador, y la Universidad de Södertörn, Suecia. Igualmente, el estudio se benefició de los comentarios de los participantes en el seminario de investigación que se realizó en la Universidad de Södertörn el 23 de mayo de 2019 y de dos evaluadores externos de la revista. Asimismo, el autor principal quiere expresar un agradecimiento especial a los queridos amigos Francisco Rhon Dávila y Pablo Ospina Peralta, quienes aportaron con comentarios muy constructivos durante nuestras conversaciones en Quito a mediados de 2019 y el inicio de 2020.

\section{Referencias bibliográficas}

ACOSTA, Alberto (2016): "Postextractivismo: Entre el discurso y la praxis. Algunas reflexiones gruesas para la acción". En Ciencia Política, año 11 No 21, pp. 287-332. https://doi.org/10.15446/cp.v11n21.60297.

ACOSTA, Alberto (2010): El Buen Vivir en el camino del post-desarrollo. Una lectura desde la Constitución de Montecristi, Policy Paper 9. Fundación Friedrich Ebert, Quito: FES-ILDIS. p. 36.

BUSTAMANTE, Teodoro (1988): Larga lucha del kakaram contra el Sucre. Quito: Abya-Yala.

CHUJI, Mónica (2010): El Sumak Kawsay: Una opción de vida. En Miradoriu (8 de noviembre). Disponible en: http://www.miradoriu.org/spip.php?article168 . [Fecha de Consulta: noviembre de 2019]. 
CLARK, A. Kim y BECKER, Marc (2007): "Indigenous Peoples and State Formation in Modern Ecuador”. En CLARK, A. Kim y BECKER, Marc (eds.). Highland Indians and the State in Modern Ecuador. Pittsburgh: University of Pittsburgh Press, pp. 1-21.

EL COMERCIO (2010): El Shuar alquila sus tierras por oro, 22 de septiembre. Disponible en: https://www.elcomercio.com/actualidad/ecuador/Shuar-alquila-tierrasoro.html [Fecha de Consulta: 3 de febrero del 2019].

EL TELÉGRAFO (2012): Quishpe auspició una exploración minera con apoyo de Holanda. 21 de marzo. Disponible en: https://www.eltelegrafo.com.ec/noticias/ actualidad/1/quishpe-auspicio-una-exploracion-minera-con-apoyo-de-holanda [Fecha de Consulta: 3 de febrero de 2019].

EL TELÉGRAFO (2014): Los Shuar reanudan la operación en minas, 30 de mayo. Disponible en: https://www.eltelegrafo.com.ec/noticias/regional/1/los-Shuarreanundan-la-operacion-en-minas [Fecha de Consulta: 2 de febrero del 2019].

EL UNIVERSO (2012): Amazónicos de Ecuador limpian pozas con mercurio. 14 de marzo. Disponible en: https://www.eluniverso.com/2012/o3/14/1/1430/amazonicos-ecuador-limpian-pozas-mercurio.html [Fecha de Consulta: 18 de junio del 2019].

ESCOBAR, Arturo (200o): "El lugar de la naturaleza y la naturaleza del lugar: ¿globalización o postdesarrollo?” En LANDER, Edgardo (ed.), La colonialidad del saber: eurocentrismo y ciencias sociales. Perspectivas Latinoamericanas. Buenos Aires: CLACSO/Consejo Latinoamericano de Ciencias Sociales, pp. 68-87.

ESCOBAR, Arturo (2005): “El “postdesarrollo” como concepto y práctica social”. En Daniel MATO (coord.), Políticas de economía, ambiente y sociedad en tiempos de globalización. Caracas: Facultad de Ciencias Económicas y Sociales, Universidad Central de Venezuela, pp. 17-31.

ESCOBAR, Arturo (2006): "Difference and Conflict in the Struggle Over Natural Resources: A Political Ecology Framework". En Development, año 49, No. 3, pp. 6-13. https://doi.org/10.1057/palgrave.development.110026.

EXPLOKEN MINERA (2018): Rendición de cuentas de Exploken Minera. Congüime: Compañía de Explotación Minera Exploken Minera S.A.

FERNÁNDEZ-SALVADOR, Elena del Consuelo (2018): The Shuar and large-scale mining in Zamora-Chinchipe, Ecuador: A study of ethnopolitics and the struggle over natural resources. Tesis doctoral. International Institute of Social Studies, Erasmus University Rotterdam. p. 291. 
GOBERNACIÓN DE ZAMORA CHINCHIPE (2014): Asociación Shuar retomará actividades mineras en Congüime. Disponible en: http://www.gobernacionzamora.gob.ec/asociacion-Shuar-retomara-actividades-mineras-en-Congüime/ [Fecha de Consulta: 2 de febrero del 2019].

GUDYNAS, Eduardo (2015): Extractivismos. Ecología, economía y política de un modo de entender el desarrollo y la Naturaleza. Cochabamba: CLAES y CEDIB. p. 456.

HOLIFIELD, Ryan (2015): "Environmental justice and political ecology". En PERRAULT, Tom, BRIDGE, Gavin, McCARTHY, James (eds.), The Routledge Handbook of Political Ecology. Routledge: London, pp. 585-597.

KAYMANTA CONSULTORES (2012): Estudio de Impacto Ambiental expost y Plan de Manejo Ambiental del proyecto minero Congüime I, formado por las concesiones mineras Congüime I, Congüime II, Congüime III, Congüime V, Congüime VI y Congüime VII fase de explotación de aluviales. Quito: ENAMI EP.

KARSTEN, Rafael (200o): La vida y la cultura de los Shuar: cazadores de cabezas del Amazonas occidental: la vida y la cultura de los Jíbaros del este del Ecuador. Quito: Abya-Yala. p. 402.

LA HORA (2012): Minería sigue preocupando en Congüime. 6 de agosto. Disponible en: https://lahora.com.ec/noticia/1101373236/minerc3ada-sigue-preocupandoen-Congüime [Fecha de Consulta: 28 de junio 2019].

LALANDER, Rickard (2014): "Rights of nature and the indigenous peoples in Bolivia and Ecuador: A Straitjacket for Progressive Development Politics?”. En Iberoamerican Journal of Development Studies, año 3, No 2, pp. 148-173. https://doi. org/10.26754/ojs_ried/ijds.137.

LALANDER, Rickard (2015): "Entre el ecocentrismo y el pragmatismo ambiental: Consideraciones inductivas sobre desarrollo, extractivismo y los derechos de la naturaleza en Bolivia y Ecuador". En Revista Chilena de Derecho y Ciencia Politica, año 6, No1, pp. 109-152. http://dx.doi.org/10.7770/rchdycp-V6N1-art837.

LALANDER, Rickard (2016): “The Ecuadorian Resource Dilemma: Sumak Kawsay or Development?". En Critical Sociology, año 42, No 4-5, pp. 623-642. https://doi. org/10.1177/0896920514557959.

LALANDER, Rickard y KRÖGER, Markus (2016): “Extractivismo y derechos étnicoterritoriales de jure y de facto en América Latina: ¿Cuán importantes son las constituciones?". En Observatorio del Desarrollo, No 23, pp. 1-22. 
LALANDER, Rickard y LEMBKE, Magnus (2018 a): “Territorialidad, Indigeneidad y Diálogo Intercultural en Ecuador: Dilemas y desafíos en el proyecto del Estado Plurinacional”. En WALDMÜLLER, Johannes M. y ALTMANN, Philipp (eds.), Territorialidades otras. Visiones alternativas de la tierra y del territorio desde Ecuador. Quito: Universidad Andina Simón Bolívar - La Tierra, pp. 183-212.

LALANDER, Rickard y LEMBKE, Magnus (2018 b): “The Andean Catch-22: Ethnicity, Class and Resource Governance in Bolivia and Ecuador". Globalizations, año 15, No 5, pp. 636-654. https://doi.org/10.1080/14747731.2018.1453189.

LALANDER, Rickard y MERIMAA, Maija (2018): “The Discursive Paradox of Environmental Conflict: Between Ecologism and Economism in Ecuador". En Forum for Development Studies, año 45, No 3, pp. 485-511. https://doi.org/10.1080/o8039 410.2018.1427622.

LATORRE TOMÁS, Sara (2012):"El movimiento ecologista popular anti-minero en el Ecuador". En Ecuador Debate, 87, pp. 123-145.

LEMBKE, Magnus, LALANDER, Rickard y GALINDO, J. Fernando (2020): “Objectivities and Trust in Ethnographic Research On and With Latin American Indigenous Peoples". En GALLARDO, Gloria L., SAUNDERS, Fred, \& SOKOLOVA, Tatiana (eds.), Co-creating Actionable Science: Reflections from the Global North and South, Cambridge Scholars Publishing. pp. 13-33.

MARTÍNEZ-ALIER, Joan (2002): The Environmentalism of the Poor, London: Elgar. p. 328.

MINERÍA EN LÍNEA (2016): Gobierno entregará concesión minera a comunidad Río Congüime, 15 de junio. Disponible en: https://mineriaenlinea.com/2016/o6/ gobierno-entregara-concesion-minera-comunidad-rio-Congüime/ [Fecha de Consulta: el 28 de junio del 2019].

MINISTERIO DEL AMBIENTE (2016): Valoración de pasivos ambientales: Informe de evaluación del daño ambiental. Caso: Minería ilegal de Congüime. Programa de Reparación Ambiental y Social-PRAS, Quito: Ministerio del Ambiente.

MINISTERIO DE MINERÍA (2016): Plan Nacional de Desarrollo del Sector Minero. Quito: Ministerio de Minería; Agencia de Regulación y Control Minero; Instituto Nacional de Investigación Geológico Minero Metalúrgico. Disponible en: http:// www.competencias.gob.ec/wp-content/uploads/2017/o6/o4PPP2016-PLAN.pdf [Fecha de Consulta: el 28 de junio del 2019].

OBSA/OBSERVATORIO DE CONFLICTOS SOCIOAMBIENTALES (2012): Análisis de percepción de conflictividad que existe en la actividad de minería artesanal de la zona de Chinapintza con enfoque especial en salud, ambiente y laboral. Loja: Universidad Técnica Particular de Loja. 
OBSA/OBSERVATORIO DE CONFLICTOS SOCIOAMBIENTALES (2017): Análisis de percepción de conflictividad que existe en la actividad de minería artesanal de la zona de Chinapintza con enfoque especial en salud, ambiente y laboral. Loja: Universidad Técnica Particular de Loja.

OBSA/ OBSERVATORIO DE CONFLICTOS SOCIOAMBIENTALES (2018 a): Percepción de problemáticas socioambientales en la comunidad minera de Congüime, Boletín No. 6, Loja: Universidad Técnica Particular de Loja.

OBSA/OBSERVATORIO DE CONFLICTOS SOCIOAMBIENTALES (2018 b): Conflictividad Socioambiental y Prácticas ancestrales en actividad minera de Congüime y Chinapintza del cantón Paquisha, Loja: Universidad Técnica Particular de Loja.

REPÚBLICA DEL ECUADOR (2008): Constitución Política del Ecuador (2008). Montecristi: Asamblea Nacional Constituyente.

SACHER, William (2015): "Minería de oro en el Ecuador. Entre actores nacionales y transnacionales”. En POVEDA, Pablo, CÓRDOVA, Héctor, PULIDO, Alejandro, SACHER, William, DE OLIVEIRA, Lino João, DARÓ, Estefanía y MARCHEGIANI, Pía (eds.). La economía del oro: Ensayos sobre la explotación en Sudamérica. La Paz: CEDLA 2015, pp. 95-132.

SACHER, William y ACOSTA, Alberto (2012): La minería a gran escala en Ecuador. Análisis y datos estadísticos sobre la minería industrial en el Ecuador. Quito. Ediciones Abya-Yala. p. 197.

SÁNCHEZ-VÁSQUEZ, Luis, ESPINOSA, Gabriela y EGUIGUREN, María-Beatriz (2016): “"Golden reality" or the "reality of gold": Artisanal mining and socio-environmental conflict in Chinapintza, Ecuador". En The Extractive Industries and Society, año 3, No1, pp. 124-128. https://doi.org/10.1016/j.exis.2015.11.004.

SENPLADES (2009): Plan Nacional para el Buen Vivir 2009-2013: Construyendo un Estado Plurinacional e Intercultural. Quito: Secretaría Nacional de Planificación y Desarrollo/SENPLADES, 2009.

SENPLADES (2013): Plan nacional para el Buen Vivir 2013-2017. Todo el mundo mejor. Quito: Secretaría Nacional de Planificación y Desarrollo/SENPLADES.

SNEDDON, Chris, HOWARTH, Richard B. y NORGAARD, Richard B. (2006): "Sustainable development in a post-Brundtland world". En Ecological Economics, año 57, No 2, pp. 253-268. https://doi.org/10.1016/j.ecolecon.2005.04.013.

SOLÍZ TORRES, María Fernanda, MALDONADO, Adolfo, VALLADARES, Carolina y MURCÍA, Diana (2012): Infancia de oro en la Cordillera del Cóndor. Quito: Clínica Ambiental. p. 154. 
SVAMPA, Maristella (2019): Las fronteras del neoextractivismo en América Latina. Conflictos socioambientales, giro ecoterritorial y nuevas dependencias. Alemania: Bielefeld University Press; FLACSO-Ecuador; Universidad de Guadalajara; Transcript Verlag. p. 142.

SVARSTAD, Hanne y BENJAMINSEN, Tor A. (2020): "Reading radical environmental justice through a political ecology lens". En Geoforum, 108. https://doi. org/10.1016/j.geoforum.2019.11.007.

VAN TEIJLINGEN, Karolien, LEIFSEN, Esben, FERNÁNDEZ-SALVADOR, Consuelo y SÁNCHEZ-VÁSQUEZ, Luis (eds.) (2017): La amazonía minada. Minería a gran escala y conflictos en el sur del Ecuador. Quito: USFQ Press y Ediciones Abya-Yala. p. 402.

WALDMÜLLER, Johannes M. y ALTMANN, Philipp (2018): “Introducción”. En WALDMÜLLER, Johannes M. y ALTMANN, Philipp (eds.), Territorialidades otras. Visiones alternativas de la tierra y del territorio desde Ecuador. Quito: Universidad Andina Simón Bolívar - La Tierra, pp. 7-44.

WRIGHT, Eric Olin (2010): Envisioning Real Utopias. London: Verso. p. 278. 